Article

\title{
Comparison the Structural, Physicochemical, and Prebiotic Properties of Litchi Pomace Dietary Fibers before and after Modification
}

\author{
Yina $\mathrm{Li}^{1,2}$, Yuanshan $\mathrm{Yu}^{1}{ }^{1}{ }^{*}$, Jijun $\mathrm{Wu}{ }^{1}$, Yujuan $\mathrm{Xu}{ }^{1}$, Gengsheng Xiao ${ }^{1}$, Lu Li ${ }^{1}$ and Haoran Liu ${ }^{1}$ \\ 1 Sericultural \& Argi-Food Research Institute, Guangdong Academy of Agricultural Sciences/Key Laboratory \\ of Functional Foods, Ministry of Agriculture and Rural Affairs/Guangdong Key Laboratory of Agricultural \\ Products Processing, Guangzhou 510610, China; yara1ne@163.com (Y.L.); guoshuwujijun@163.com (J.W.); \\ guoshuxuyujuan@163.com (Y.X.); guoshuxgs@163.com (G.X.); lilu045@163.com (L.L.); \\ winstonliu111@163.com (H.L.) \\ 2 College of Food Sciences, South China Agricultural University, Guangzhou 510642, China \\ * Correspondence: yuyuanshan@gdaas.cn; Tel.: +86-159-7559-6649
}

check for updates

Citation: Li, Y.; Yu, Y.; Wu, J.; Xu, Y.; Xiao, G.; Li, L.; Liu, H. Comparison the Structural, Physicochemical, and Prebiotic Properties of Litchi Pomace Dietary Fibers before and after Modification. Foods 2022, 11, 248. https://doi.org/10.3390/ foods11030248

Academic Editors: Michela Verni and Federico Casanova

Received: 8 December 2021 Accepted: 14 January 2022 Published: 18 January 2022

Publisher's Note: MDPI stays neutral with regard to jurisdictional claims in published maps and institutional affiliations.

Copyright: (c) 2022 by the authors. Licensee MDPI, Basel, Switzerland. This article is an open access article distributed under the terms and conditions of the Creative Commons Attribution (CC BY) license (https:// creativecommons.org/licenses/by/ $4.0 /)$.

\begin{abstract}
Litchi pomace, a by-product of litchi processing, is rich in dietary fiber. Soluble and insoluble dietary fibers were extracted from litchi pomace, and insoluble dietary fiber was modified by ultrasonic enzymatic treatment to obtain modified soluble and insoluble dietary fibers. The structural, physicochemical, and functional properties of the dietary fiber samples were evaluated and compared. It was found that all dietary fiber samples displayed typical polysaccharide absorption spectra, with arabinose being the most abundant monosaccharide component. Soluble dietary fibers from litchi pomace were morphologically fragmented and relatively smooth, with relatively high swelling capacity, whereas the insoluble dietary fibers possessed wrinkles and porous structures on the surface, as well as higher water holding capacity. Additionally, soluble dietary fiber content of litchi pomace was successfully increased by $6.32 \pm 0.14 \%$ after ultrasonic enzymatic modification, and its arabinose content and apparent viscosity were also significantly increased. Further, the soluble dietary fibers exhibited superior radical scavenging ability and significantly stimulated the growth of probiotic bacterial species. Taken together, this study suggested that dietary fiber from litchi pomace could be a promising ingredient for functional foods industry.
\end{abstract}

Keywords: litchi pomace; dietary fiber; monosaccharide composition; structure; prebiotic activity

\section{Introduction}

Litchi (Litchi chinensis Sonn.) is an evergreen tree of the Sapindaceae family, with the main growing countries being China, Vietnam, Thailand, and India [1]. In China, Huaizhi and Heiye are the main litchi cultivars used for further processing to produce value-added products such as dried litchi, litchi juice, and litchi wine [2]. However, the resulting pomace, pericarp, and seeds are frequently discarded, which have been reported to contain diverse nutrients and bioactive compounds, including polysaccharides, crude fiber, and polyphenols [3]. Therefore, increasing research has focused on studying the utilization of nutrients and bioactive compounds from litchi fruit waste for the reduction of environmental burden and the potential application in food and/or functional food industry [4-6].

Litchi pomace produced by the process is more often used for feed production. At present, research on the structural and functional properties of dietary fiber extracted from litchi pomace is limited compared to polysaccharides and polyphenols [7-9]. Dietary fiber is a broad category of indigestible food ingredients and roughly classified as water-soluble dietary fiber and water-insoluble dietary fiber according to their solubility in water. Specifically, water-soluble dietary fiber mainly includes pentosan, soluble hemicellulose, gum, 
and pectin, while cellulose, insoluble hemicellulose and lignin are the major compositions of IDF [10]. Multiple animal studies and human trials have demonstrated that dietary fiber possess several biological activities, such as improving intestinal absorption, increasing satiety, enhancing immune function, and promoting colon health, which are determined by the source of dietary fiber with different chemical structures and compositions [11]. Moreover, many studies have been conducted to modify the structure and composition of dietary fiber through different treatments to enhance and modify its function. The single modification method has its limitations, whereas the combined modification possesses a stronger modifying effect $[12,13]$. Nowadays, ultrasonic enzymatic treatment is more applied to modify dietary fiber, owing to its safety, low damage to the molecular structure of dietary fiber, and its effectiveness in increasing the water-soluble dietary fiber content [14].

To better utilize the litchi fruit waste and explore the potential application of litchi dietary fiber in food and/or functional food industry, the current study aimed to compare the differences in structural and functional properties of dietary fibers obtained from litchi pomace, so as to provide ideas and theoretical basis for the further processing of litchi pomace.

\section{Materials and Methods}

\subsection{Materials}

Litchi pomace (cv. Huaizhi) was provided by Guangzhou Shunchangyuan Green Food Co., Ltd. (Guangzhou, Guangdong Province, China). Prior to dietary fiber extraction, litchi pomace was desugared by Saccharomyces cerevisiae fermentation. Briefly, litchi pomace was heated in a water bath at $80{ }^{\circ} \mathrm{C}$ for $20 \mathrm{~min}, 0.02 \%(w / w)$ activated Saccharomyces cerevisiae was added after returning to room temperature, and the mixture was placed in a constant temperature incubator for fermentation at $30^{\circ} \mathrm{C}$ for $24 \mathrm{~h}$, then dried with the moisture content of 8 to $12 \%$ by weight using the hot air vacuum drying. The dried sample was crushed and passed through a 60-mesh sieve to obtain the desugared litchi pomace powder, which was kept in a desiccator for later use. The monosaccharide standards were HPLC grade, and were purchased from Shanghai Yuanye Biological Technology Co., LTD (Shanghai, China). Other chemicals used in this study were of analytical grade.

\subsection{Preparation of Dietary Fiber from Litchi Pomace}

Dietary fiber from litchi pomace was prepared as previously described by Wu et al. [15] with minor modifications. Initially, the desugared litchi pomace powder was mixed with distilled water $(1: 20, w: v)$ and hydrolyzed by $0.2 \%(w / w, 2000 \mathrm{U} / \mathrm{g}) \alpha$-amylase in a shaking bath $(150 \mathrm{r} / \mathrm{min})$ at $\mathrm{pH} 6.0,60{ }^{\circ} \mathrm{C}$ for $1 \mathrm{~h}$. Thereafter, $1.0 \%(w / w, 100 \mathrm{U} / \mathrm{mg})$ neutral protease was added and incubated at $\mathrm{pH} 7.0,50{ }^{\circ} \mathrm{C}$ for $1.5 \mathrm{~h}$. The treated mixture was centrifuged at $6000 \times g$ for $10 \mathrm{~min}$ after the inactivation of enzyme in boiling water bath for $10 \mathrm{~min}$. The resulting residue was washed with distilled water, $95 \%(v / v)$ ethanol, and acetone and then freeze-dried in a vacuum freezer to obtain the water-insoluble dietary fiber (IDF), whereas the supernatant was vacuum-concentrated $\left(50{ }^{\circ} \mathrm{C}, 40 \mathrm{rpm}\right)$ and precipitated with four times volumes of $95 \%$ ethanol at room temperature for $12 \mathrm{~h}$. After centrifugation at $6000 \times g$ for $10 \mathrm{~min}$, the precipitate was collected and dissolved in distilled water to remove ethanol by vacuum rotary evaporation before lyophilization to obtain the water-soluble dietary fiber (SDF). The yields of SDF and IDF obtained from litchi pomace were $7.28 \pm 0.13 \%$ and $69.30 \pm 0.78 \%$, respectively.

\subsection{Ultrasonic Enzymatic Modification of IDF from Litchi Pomace}

Ultrasonic enzymatic modification was conducted as the following steps: Initially, IDF was mixed with distilled water $(1: 20, w: v)$ and sonicated at $450 \mathrm{~W}, 50{ }^{\circ} \mathrm{C}$ for $30 \mathrm{~min}$ using the ultrasonic bath (DL-800B, Zhixin, China). Subsequently, $50 \mu \mathrm{L} / \mathrm{g}$ of cellulase (700 EGU/g) was added, and the mixture was incubated for $3 \mathrm{~h}$ at $50{ }^{\circ} \mathrm{C}$ with constant shaking $(150 \mathrm{rpm})$. After the incubation, the cellulase was inactivated, followed by the centrifugation of mixture, and the resulting supernatant and precipitation were treated 
by aforementioned process. The water-soluble dietary fiber sample obtained was marked as M-SDF, and the water-insoluble dietary fiber sample obtained was marked as M-IDF. The yields of M-SDF and M-IDF obtained from litchi pomace were $6.32 \pm 0.14 \%$ and $55.67 \pm 0.53 \%$, respectively.

\subsection{Monosaccharide Composition}

The monosaccharide composition of dietary fibers from litchi pomace was measured by 1-phenyl-3-methyl-5-pyrazolone (PMP) derivatization and high-performance liquid chromatography (HPLC, Agilent 1200 series, Mundelein, IL, USA) with a Wondasil C18 column (4.6 mm $\times 250 \mathrm{~mm}$ i.d., $5 \mu \mathrm{m}$ particle size) according to the method of Liu et al. [16] The standard monosaccharides, including mannose, ribose, rhamnose, galactose acid, glucose, galactose, xylose, and arabinose, were used to analyze the monosaccharides in hydrolyzed samples. Chromatographic separation was carried out using $0.05 \mathrm{M}$ sodium phosphate buffer ( $\mathrm{pH}$ 6.85) and acetonitrile at a ratio of 82:18 (v:v) as mobile phase at the flow rate of $1 \mathrm{~mL} / \mathrm{min}$. The detection wavelength was set as $250 \mathrm{~nm}$.

\subsection{Scanning Electron Microscopy (SEM)}

The dietary fiber samples were mounted on an aluminum stub with double-sided stick tape and coated with a $10 \mathrm{~nm}$ gold layer. An electron microscope (S-3000N, Hitachi Ltd., Tokyo, Japan) captured the scanning images at an accelerating voltage of $20.0 \mathrm{kV}$. The micrographs were taken at $\times 1000$ magnification (scale bar $50 \mu \mathrm{m}$ ).

\subsection{Fourier Transform Infrared Spectroscopy (FTIR)}

Changes in the molecular structure of samples were obtained at room temperature using FTIR (VERTEX 70, Bruker, Karlsruhe, Germany). The dry sample was mixed with $\mathrm{KBr}$ powder under infrared irradiation and pressed into a tablet. Spectra were collected in the range of $4000-400 \mathrm{~cm}^{-1}$ with a resolution of $4 \mathrm{~cm}^{-1}$ [17].

\subsection{Hydration Properties}

Hydration properties, including the water holding capacity (WHC), swelling capacity (SC), and water solubility (WS), were determined by the methods described by Shen et al. [18]. The WHC, SC, and WS were reported as mean value of three determinations per sample.

\subsection{Rheological Property}

The viscosity of water-soluble dietary fiber samples was measured by an AR1500EX rheometer (TA Instruments Ltd., New Castle, DE, USA) equipped with a cone and plane geometry system (40 mm diameter, $1 \mathrm{~mm}$ gap). In steady shear tests, the steady flow behaviors of water-soluble dietary fiber samples with different concentrations $(4,8$, and $12 \%, w / v)$ were measured at a $0.1-100 \mathrm{~s}^{-1}$ shear rate range and $25^{\circ} \mathrm{C}$.

\subsection{The Radical Scavenging Activity}

The antioxidant active ingredient was extracted on the basis of the previous method [19], and the radical scavenging activity was measured via ABTS assay as per the method of RuizTorralba et al. [20] with slight modifications. Briefly, $20 \mu \mathrm{L}$ of each sample extract/sample aqueous solution with different mass concentrations were individually placed in a 96-well polystyrene microplate, after which $200 \mu \mathrm{L}$ of the working ABTS solution was added. The mixture was stored at room temperature in darkness for $10 \mathrm{~min}$, and the absorbance was measured by the microplate reader at $734 \mathrm{~nm}$. The percent scavenging activity was calculated as follows:

$$
\text { ABTS radical scavenging activity }(\%)=100 \times\left[1-\left(\mathrm{A}_{1}-\mathrm{A}_{2}\right) / \mathrm{A}_{0}\right]
$$


where $A_{0}$ is the absorbance of the ABTS solution with ethanol instead of sample, $A_{1}$ is the absorbance of the ABTS solution with sample, and $\mathrm{A}_{2}$ is the absorbance of the sample with anhydrous methanol instead of ABTS solution

\subsection{In Vitro Probiotic Activity}

In this study, both Lactobacillus acidophilus and Lactobacillus plantarum were provided by the microbiology laboratory of Sericultural and Agri-Food Research Institute (Guangdong, China) and were used to evaluate the probiotic activity of SDF and M-SDF. The preparation of inoculants was determined in accordance with steps described by Okolie et al. [21]. First, the sugar-free MRS base medium was prepared as described by Safoura et al. [22]. Then, glucose (negative control), inulin (positive control), SDF, and M-SDF were added to sugar-free MRS base medium separately at concentrations of $2 \%(w / v)$, while sugar-free MRS basal medium served as a blank control. All MRS media were autoclaved at $121{ }^{\circ} \mathrm{C}$ for $20 \mathrm{~min}$ and cooled to $50{ }^{\circ} \mathrm{C}$, followed by the inoculation of $2 \%(v / v)$ above bacterial suspensions and incubation at $37^{\circ} \mathrm{C}$ for $24 \mathrm{~h}$. Growth of each strain was monitored by measuring $\mathrm{pH}$ and the optical density (OD) of 10 -fold diluted at $600 \mathrm{~nm}$.

\subsection{Statistical Analysis}

All measurements were performed at least in triplicate, and the results were expressed as the mean values with their standard deviation. Statistical analyses were carried using the SPSS 22.0 software (SPSS Inc., Chicago, IL, USA). Data were analyzed using one-way ANOVA and Duncan's test. $p<0.05$ was considered to be statistically significant.

\section{Results and Discussion}

\subsection{Structural Characterization}

\subsubsection{Monosaccharide Composition Analysis}

A total of eight monosaccharides were detected in all four dietary fiber samples, and the monosaccharide content varied among four different dietary fiber samples (Table 1). The highest content was arabinose $(83.14 \pm 0.39-233.11 \pm 1.84 \mathrm{mg} / \mathrm{g})$, which was higher than that reported in defatted coconut flour $(11.84 \pm 0.82 \mathrm{mg} / \mathrm{g})$ and pear pomace dietary fiber $(20.40 \pm 6.30 \mathrm{mg} / \mathrm{g})$ [23,24]. Wang et al. [25] found that glucose was the main monosaccharide in orange SDF $(64.00 \pm 1.73 \mathrm{mg} / \mathrm{g})$, while the main monosaccharide of the SDFs from grapefruit and lemon was arabinose $(100.72 \pm 2.43 \mathrm{mg} / \mathrm{g}$ and $58.82 \pm 1.84 \mathrm{mg} / \mathrm{g})$. The abundance of arabinose is characteristic of dietary fiber from litchi pomace, which has been reported to have physiological activities such as regulating lipid metabolism, affecting intestinal microbiota and metabolism [26,27]. Further, SDF and M-SDF contained significantly higher levels of galacturonic acid, arabinose, rhamnose, and galactose, which were typical constituents of pectin [28], and thus it may be concluded that arabinose-rich pectin is the key component of soluble dietary fiber from litchi pomace. The high contents of arabinose, glucose, and xylose in IDF and M-IDF indicated that arabinoxylan and cellulose may be the main components of insoluble dietary fiber from litchi pomace [29]. In addition, M-SDF contained more galacturonic acid, glucose, and arabinose glucose than SDF, whereas the concentrations of galacturonic acid, xylose, and arabinose in M-IDF were lower than that in IDF, indicating that ultrasonic enzymatic modification may lead to the hydrolysis of cellulose in the cell wall and the release of some xylan hemicellulose, thus facilitating the conversion of insoluble dietary fiber to soluble dietary fiber [30].

\subsubsection{SEM Analysis}

As depicted in Figure 1, the morphological characterization of the dietary fiber samples at magnification times of 1000 was observed using SEM. These micro images clearly indicated the significant variations of surface topography among the dietary fiber samples. Compared to SDF, IDF had rougher topography with obvious wrinkles, which might have been the result of different dietary fibers types. In the study of Lyu et al. [31], the tissue state of high-purity insoluble fiber from soybean dregs showed hierarchical and low 
aggregation degree. The finding of Chen et al. [32] revealed that wheat-soluble dietary fiber had a relatively flat and loose structure with a certain gap between fibers, whereas the surface of wheat-insoluble dietary fiber was irregular with a large number of cracks and small clumps. In addition, the microstructure of the dietary fibers obtained by ultrasonic enzymatic modification showed significant changes in morphology, with M-SDF appearing more fragmented than SDF and M-IDF, presenting cellular network structure with stronger porosity than IDF, which indicated that ultrasonic enzymatic modification can destroy the matrix of cellulose, hemicellulose, and lignin, thus promoting the transformation of IDF to M-SDF [33]. Similar results were obtained by Ma et al. [17]. The physiochemical properties of dietary fiber are determined by its microstructure. Porous and folded structure can increase the specific surface area and expose more polar groups, consequently promoting the adsorption and binding of water, which further affects its application in food [34].

Table 1. Monosaccharide compositions of SDF, M-SDF, IDF, and M-IDF.

\begin{tabular}{ccccc}
\hline mg/g & SDF & M-SDF & IDF & M-IDF \\
\hline Mannose & $37.49 \pm 0.16^{\mathrm{a}}$ & $27.22 \pm 0.69^{\mathrm{b}}$ & $26.63 \pm 1.27^{\mathrm{b}}$ & $25.44 \pm 1.29^{\mathrm{b}}$ \\
Ribose & $0.74 \pm 0.19^{\mathrm{a}}$ & $0.16 \pm 0.01^{\mathrm{b}}$ & $0.41 \pm 0.04^{\mathrm{b}}$ & $0.25 \pm 0.02^{\mathrm{b}}$ \\
Rhamnose & $17.81 \pm 0.13^{\mathrm{a}}$ & $18.63 \pm 0.65^{\mathrm{a}}$ & $8.43 \pm 0.49^{\mathrm{b}}$ & $5.86 \pm 0.18^{\mathrm{c}}$ \\
Galacturonic acid & $111.87 \pm 4.54^{\mathrm{b}}$ & $133.27 \pm 6.46^{\mathrm{a}}$ & $25.38 \pm 1.27^{\mathrm{c}}$ & $11.27 \pm 0.48^{\mathrm{d}}$ \\
Glucose & $44.40 \pm 1.87^{\mathrm{c}}$ & $79.17 \pm 0.55^{\mathrm{a}}$ & $50.14 \pm 0.98^{\mathrm{b}}$ & $49.09 \pm 1.88^{\mathrm{b}}$ \\
Galactose & $41.26 \pm 0.14^{\mathrm{a}}$ & $30.73 \pm 1.09^{\mathrm{b}}$ & $20.55 \pm 0.27^{\mathrm{c}}$ & $15.75 \pm 0.15^{\mathrm{d}}$ \\
Xylose & $3.21 \pm 0.06^{\mathrm{d}}$ & $7.03 \pm 0.10^{\mathrm{c}}$ & $21.90 \pm 0.38^{\mathrm{a}}$ & $12.32 \pm 0.86^{\mathrm{b}}$ \\
Arabinose & $187.02 \pm 2.17^{\mathrm{b}}$ & $233.11 \pm 1.84^{\mathrm{a}}$ & $102.00 \pm 0.47^{\mathrm{c}}$ & $83.14 \pm 0.39^{\mathrm{d}}$ \\
\hline
\end{tabular}

Different letters $(\mathrm{a}, \mathrm{b}, \mathrm{c}, \mathrm{d})$ in the same row indicate significantly different means at $p<0.05$ (Duncan's test).

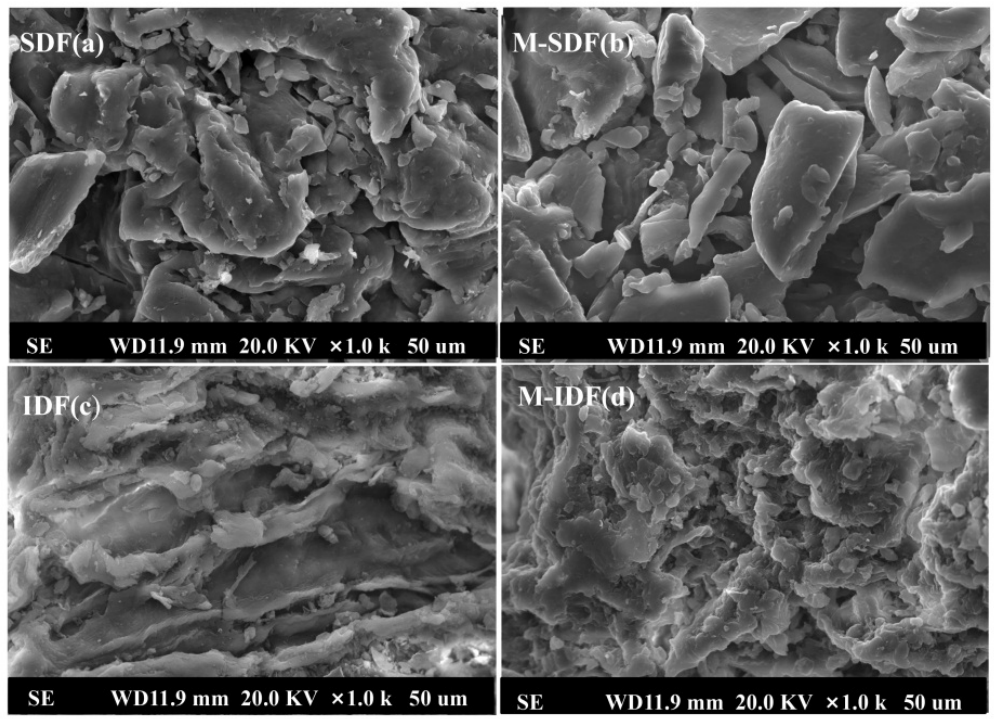

Figure 1. SEM images of SDF (a), M-SDF (b), IDF (c), and M-IDF (d). Magnification: $1000 \times$ (scale bar $50 \mu \mathrm{m})$.

\subsubsection{FTIR Analysis}

The infrared spectra of all dietary fiber samples displayed the characteristic absorption peaks of cellulose polysaccharides (Figure 2). The overall peak intensity of SDF and MSDF was significantly higher than that of IDF and M-IDF, indicating that SDF and M-SDF had more typical polysaccharide complex structures. The wide absorption band near $3400 \mathrm{~cm}^{-1}$ was caused by the stretching of $\mathrm{O}-\mathrm{H}$ groups in polysaccharides. The peak intensity of M-SDF was relatively high at this wavelength, indicating that there were more hydrogen bonds in the associative state, which may have been related to M-SDF containing more gels (galactose acid) and hemicelluloses (mannose, glucose, galactose, and arabinose) (Table 1) [30]. The absorption peak near $1620 \mathrm{~cm}^{-1}$ was the stretching vibration absorption of $\mathrm{C}=\mathrm{O}$, suggesting the presence of amide groups. The absorption peak in 
the range of $1200-1400 \mathrm{~cm}^{-1}$ was caused by the angular vibrations of $\mathrm{C}-\mathrm{H}$, representing the typical structure of a carbohydrate skeleton. The absorption peak in the range of $1200-1000 \mathrm{~cm}^{-1}$ corresponded to the stretching vibrations of $\mathrm{C}-\mathrm{C}, \mathrm{C}-\mathrm{O}$, and $\mathrm{C}-\mathrm{O}-\mathrm{C}$, which were frequently reported as the presence of sugar aldehyde groups [35]. The modified dietary fibers presented stronger absorption peaks at the wavelength of these characteristic romaegions, which indicated that the supramolecular structure and reactive groups of litchi pomace dietary fiber were changed by the ultrasonic enzymatic modification. In addition, IDF and M-IDF were observed to have characteristic absorption peaks of aromatic lignin hydrocarbons near $1530 \mathrm{~cm}^{-1}$ [36], while SDF and M-SDF showed clearly characteristic absorption peaks of $\beta$-glucoside bond, furanose, and $\alpha$ - and $\beta$-pyranose in the range of $1000-700 \mathrm{~cm}^{-1}$ [37].

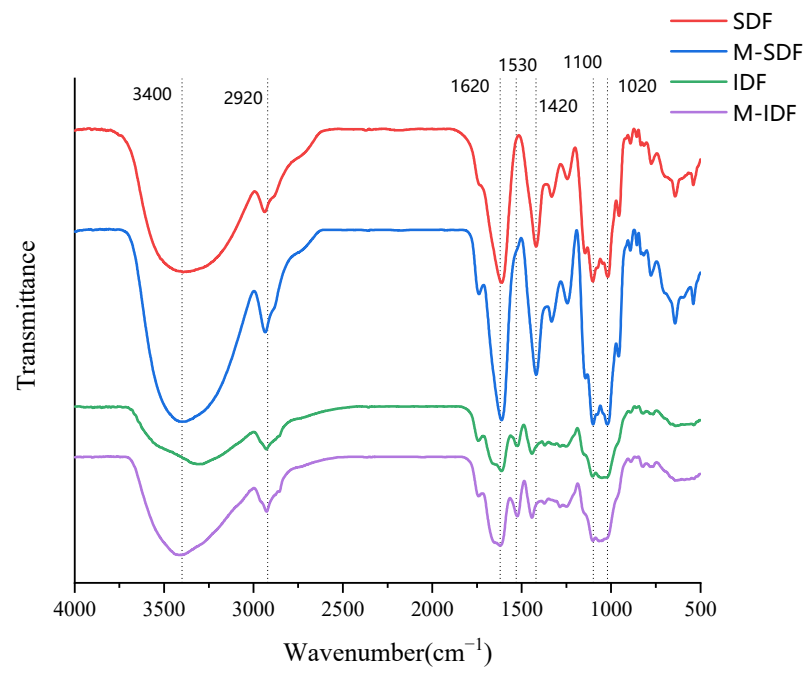

Figure 2. FTIR of SDF, M-SDF, IDF, and M-IDF.

\subsection{Physicochemical Properties}

\subsubsection{Hydration Properties}

Hydration properties of the dietary fiber samples are presented in Table 2. WHC refers to the ability of wet materials to retain water under external force (centrifugal force or compression, etc.). SC measures the change of the total volume of materials and water, while WS reflects the degree to which materials can be dissolved by water at a certain temperature [38]. As observed from the results, SDF had the highest SC and WS, while the WHC of IDF was higher than that of SDF. These results were consistent with the findings of Zhu et al. [39], which might have been due to greater fiber porosity and hydrogen bond content in IDF. After ultrasonic enzymatic modification, the SC of M-IDF was $7.18 \pm 0.25 \mathrm{~mL} / \mathrm{g}$, whereas the WHC decreased to $9.07 \pm 0.09 \mathrm{~g} / \mathrm{g}$, which were higher relative to that of apple fiber $(6.89 \pm 0.11 \mathrm{~mL} / \mathrm{g}$ and $6.12 \pm 0.11 \mathrm{~g} / \mathrm{g})$ [40]. A previous work found that the SC and WHC were decreased in rice bran dietary fiber after cellulase modification [33], which was attributed to cellulase treatment changing the contents of hydrophilic components such as hemicellulose and cellulose. Hydration properties of dietary fiber are closely related to its source, structural morphology, porosity, and processing parameters [41]. Typically, the high WHC and SC indicate that litchi pomace dietary fiber may be considered for use in food processing to modify texture and avoid dehydration in formula foods.

Table 2. Hydration properties of SDF, M-SDF, IDF, and M-IDF.

\begin{tabular}{ccccc}
\hline mg/g & SDF & M-SDF & IDF & M-IDF \\
\hline WHC (g/g) & $6.75 \pm 0.09^{\mathrm{c}}$ & $6.9 \pm 0.13^{\mathrm{c}}$ & $9.69 \pm 0.2^{\mathrm{a}}$ & $9.07 \pm 0.09^{\mathrm{b}}$ \\
SC (mL/g) & $8.63 \pm 0.18^{\mathrm{a}}$ & $7.75 \pm 0.35^{\mathrm{b}}$ & $6.65 \pm 0.28^{\mathrm{c}}$ & $7.18 \pm 0.25^{\mathrm{b}, \mathrm{c}}$ \\
WS (\%) & $83.1 \pm 1.76^{\mathrm{a}}$ & $78.34 \pm 0.2^{\mathrm{b}}$ & $10.22 \pm 0.17^{\mathrm{c}}$ & $9.29^{\mathrm{b}} \pm 0.32^{\mathrm{c}}$ \\
\hline
\end{tabular}

Different letters $(\mathrm{a}, \mathrm{b}, \mathrm{c})$ in the same row indicate significantly different means at $p<0.05$ (Duncan's test). 


\subsubsection{Rheological Properties}

The steady flow test curves of SDF and M-SDF are plotted in Figure 3. The apparent viscosity of SDF and M-SDF decreased gradually with the increase of shear rate at room temperature, presenting shear dilution phenomenon, which showed that SDF and MSDF belonged to pseudoplastic non-Newtonian fluids. Moreover, with the increase of concentration, the apparent viscosities of SDF and M-SDF increased accordingly. It can be seen that the concentration of the sample had a direct and nonlinear effect on the viscosities of the constant temperature solution, which was consistent with the results of Feng et al. [42]. This might have been due to the fact that the interaction force among the SDFs molecules elevated at high concentration, which increased the degree of cross-linking and polymerization of substances. Additionally, at the same concentration and shear rate, the apparent viscosity of M-SDF was greater than that of SDF, which may have been associated with the greater pectin structures and longer the molecular chain length of MSDF $[24,43]$. Previous studies have shown that viscosity is one of the important properties of SDF, which is closely related to the ability of SDF to delay and reduce the absorption of food components in the digestive tract and reduce the postprandial blood glucose response [44]. Thus, we speculated that M-SDF may have a better in vivo physiological activity than SDF.

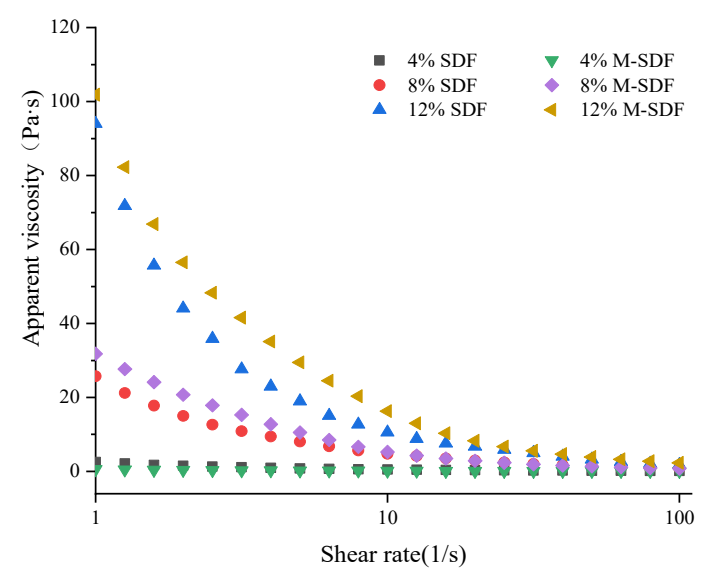

Figure 3. Viscosity curves of SDF and M-SDF at 4, 8, and $12 \%(w / v)$.

\subsection{Functional Properties}

\subsubsection{The Radical Scavenging Activity}

As shown in Figure 4, both types of the dietary fiber samples exhibited radical scavenging activity with a clear dose-dependent manner. At the dose of $5.0 \mathrm{mg} / \mathrm{mL}$, the ABTS radical scavenging activity of SDF, M-SDF, IDF, and M-IDF extracts were, respectively, $50.24 \%, 19.08 \%, 58.92 \%$, and 59.95\% (Figure $4 \mathrm{a}$ ), which was similar to that reported in black mulberry [45]. Consistent with the findings of a previous work [46], IDF extract was observed to possess higher radical scavenging as compared to SDF extract, which can be attributed to a higher amount of phenols that were co-extracted with the molecule [47]. The hydroxyl groups of phenolic compounds could donate electrons or hydrogen atoms to enhance the antioxidant activity [48]. In addition, at the dose of $3.0 \mathrm{mg} / \mathrm{mL}$, the ABTS radical scavenging activities of dietary fiber aqueous solution were $82.24 \%, 65.20 \%, 27.90 \%$, and $18.20 \%$, respectively (Figure $4 \mathrm{~b}$ ). The radical scavenging activity of SDF and M-SDF aqueous solution was significantly higher than that of IDF and M-IDF aqueous solution, which was probably due to its higher content of uronic acid and the presence of hydroxyl groups in the main backbone [32]. SDF possessed relatively higher radical scavenging capacity than M-SDF, which may be related to its glycosidic bonding and the molecular chain binding substances [49]. 


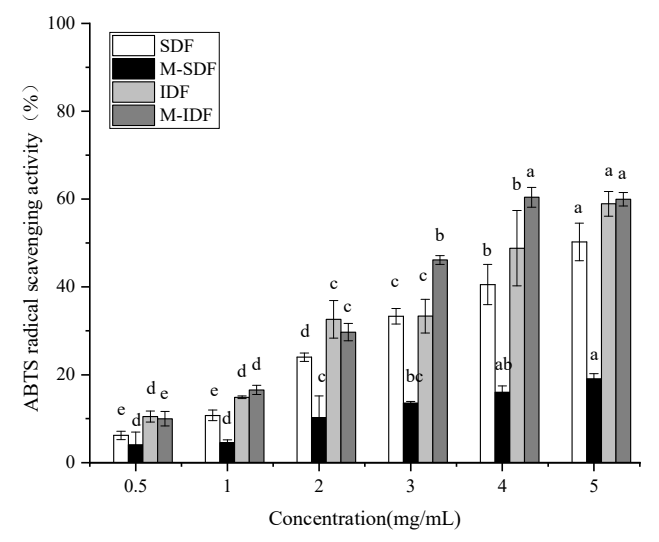

(a)

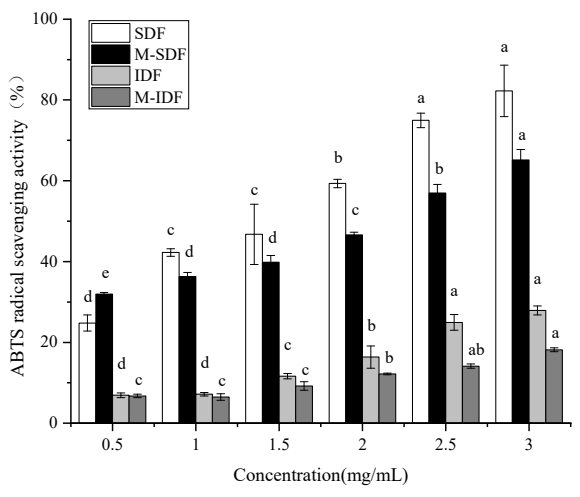

(b)

Figure 4. (a) ABTS radical scavenging activities of sample extracts; (b) ABTS radical scavenging activities of sample aqueous solutions. Different letters $(\mathrm{a}, \mathrm{b}, \mathrm{c}, \mathrm{d}, \mathrm{e})$ in the same row indicate significantly different means at $p<0.05$ (Duncan's test).

\subsubsection{In Vitro Probiotic Activity}

In this study, we evaluated the ability of Lactobacillus acidophilus and Lactobacillus plantarum to utilize SDF and M-SDF as their carbon sources in glucose-free MRS base medium in comparison with inulin or glucose as sole carbon source. As showed in Figure 5, the growth of Lactobacillus acidophilus and Lactobacillus plantarum in the MRS medium supplemented with glucose was significantly higher than other media after $24 \mathrm{~h}$ of fermentation. The depletion of carbon sources promoted the growth of probiotics and correspondingly lowered the $\mathrm{pH}$ of the medium. Our results were similar to that of Chen et al. [50]. SDF and M-SDF significantly improved the growth of two bacterial species as compared to the sugar-free MRS medium, but its probiotic effect was weaker than that of inulin. In addition, M-SDF promoted the growth of Lactobacillus plantarum better than SDF at the concentration of $2.0 \%$, which may have been due to the complex microstructure and the different monosaccharide ratios that affect accessibility and fermentability of dietary fiber. In living organisms, most of glucose is expected to be absorbed into the blood, rather than stimulating bacterial growth in the large intestine [51]. Related studies have shown that dietary fiber can resist the hydrolysis by digestive enzymes in the upper gut and undergo fermentation in the lower gut by the gut microbiota, stimulating the growth and activity of beneficial bacterial populations $[52,53]$. Therefore, it could be speculated that SDF and M-SDF are good substrates for promoting probiotic growth.

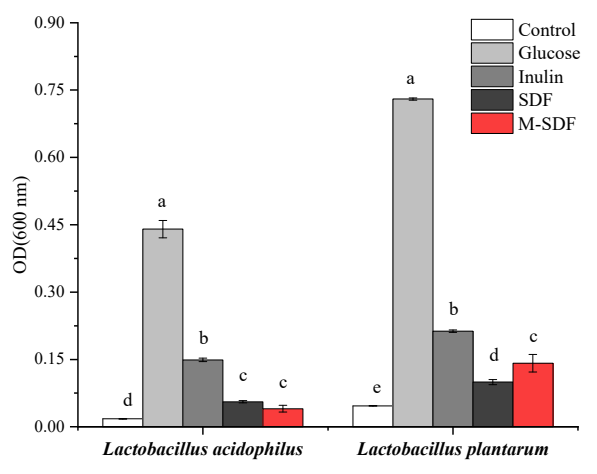

(a)

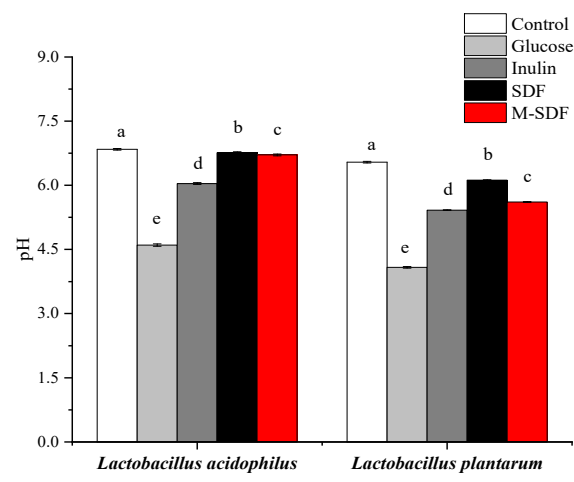

(b)

Figure 5. (a) OD value of MRS medium; (b) pH value of MRS medium. Different letters (a, b, c, d, e) in the same row indicate significantly different means at $p<0.05$ (Duncan's test). 


\section{Conclusions}

This study reports the first data in the literature for the dietary fiber samples obtained from litchi pomace and modified by ultrasonic enzymatic treatment, contributing to better understand the structural and functional properties of litchi pomace dietary fibers. The results indicated that a total of eight monosaccharides were detected in the four dietary fiber samples, with arabinose being the most abundant. All dietary fiber samples had the typical polysaccharide functional groups and different morphology. Additionally, SDF exhibited superior SC and WS, while IDF exhibited greater WHC. Compared to other fibers, the polysaccharide constituents of litchi pomace dietary fibers were strongly hydrophilic, and those materials might be well suited for formulated foods to reduce calories, avoid syneresis, prolong stability, and modify the texture. Moreover, soluble dietary fiber content of litchi pomace was successfully increased with enhanced arabinose content and apparent viscosity after ultrasonic enzymatic modification. Both SDF and M-SDF exhibited superior radical scavenging ability and potential as a source of prebiotics. Considering their ideal functional properties in vitro, we suggest soluble dietary fiber from litchi pomace could be exploited as an ingredient in functional foods. The functional activity in vivo of litchi pomace dietary fiber and its physicochemical and nutritional interactions with other ingredients in the food system are worthy of further study.

Author Contributions: Conceptualization, Y.Y. and Y.L.; methodology, Y.Y.; software, Y.L. and L.L.; validation, G.X., J.W. and Y.X.; formal analysis, Y.Y.; investigation, Y.L.; resources, Y.X.; data curation, Y.Y., L.L. and Y.L.; writing—original draft preparation, Y.L.; writing—review and editing, Y.L. and H.L.; visualization, H.L.; supervision, G.X. and J.W.; project administration, Y.Y.; funding acquisition, Y.X. All authors have read and agreed to the published version of the manuscript.

Funding: This research was funded by agricultural advantage industry discipline team projects of Guangdong Academy of Agricultural Sciences in the 14th Five-Year Period (no. 202109TD), Guangdong Provincial Special Fund for Litchi Industry Innovation Team of Modern Agriculture Industry Technology Innovation Teams (no. 2021KJ107-3), and personnel training program of Guangdong Academy of Agricultural Sciences (no. R2020PY-JG010).

Institutional Review Board Statement: Not applicable.

Informed Consent Statement: Not applicable.

Data Availability Statement: All data from this study have been reported in the manuscript.

Acknowledgments: The authors would like to thank all those who contributed directly or indirectly to the project.

Conflicts of Interest: The authors declare no conflict of interest and that the funder had no role in the study design and implementation.

\section{References}

1. Pareek, S. Nutritional and Biochemical Composition of Lychee (Litchi chinensis Sonn.) Cultivars. In Nutritional Composition of Fruit Cultivars; Simmonds, M.S.J., Preedy, V.R., Eds.; Elsevier: Amsterdam, The Netherlands, 2016. [CrossRef]

2. Jiang, Y.M.; Wang, Y.; Song, L.; Liu, H.; Lichter, A.; Kerdchoechuen, O.; Joyce, D.C.; Shi, J. Postharvest characteristics and handling of litchi fruit-An overview. Aust. J. Exp. Agric. 2006, 46, 1541-1556. [CrossRef]

3. Zhu, X.-R.; Wang, H.; Sun, J.; Yang, B.; Duan, X.-W.; Jiang, Y.-M. Pericarp and seed of litchi and longan fruits: Constituent, extraction, bioactive activity, and potential utilization. J. Zhejiang Univ. Sci. B 2019, 20, 503-512. [CrossRef]

4. Pop, C.; Suharoschi, R.; Pop, O. Dietary Fiber and Prebiotic Compounds in Fruits and Vegetables Food Waste. Sustainability 2021, 13, 7219. [CrossRef]

5. Emanuele, S.; Lauricella, M.; Calvaruso, G.; D'Anneo, A.; Giuliano, M. Litchi chinensis as a Functional Food and a Source of Antitumor Compounds: An Overview and a Description of Biochemical Pathways. Nutrients 2017, 9, 992. [CrossRef]

6. Su, D.; Zhang, R.; Zhang, C.; Huang, F.; Xiao, J.; Deng, Y.; Wei, Z.; Zhang, Y.; Chi, J.; Zhang, M. Phenolic-rich lychee (Litchi chinensis Sonn.) pulp extracts offer hepatoprotection against restraint stress-induced liver injury in mice by modulating mitochondrial dysfunction. Food Funct. 2016, 7, 508-515. [CrossRef]

7. Huang, F.; Zhang, R.; Liu, Y.; Xiao, J.; Liu, L.; Wei, Z.; Yi, Y.; Zhang, M.; Liu, D. Dietary litchi pulp polysaccharides could enhance immunomodulatory and antioxidant effects in mice. Int. J. Biol. Macromol. 2016, 92, 1067-1073. [CrossRef] [PubMed] 
8. Su, D.; Zhang, R.; Hou, F.; Zhang, M.; Guo, J.; Huang, F.; Deng, Y.; Wei, Z. Comparison of the free and bound phenolic profiles and cellular antioxidant activities of litchi pulp extracts from different solvents. BMC Complement. Altern. Med. 2014, 14, 9. [CrossRef]

9. Zhao, L.; Wang, K.; Wang, K.; Zhu, J.; Hu, Z. Nutrient components, health benefits, and safety of litchi (Litchi chinensis Sonn.): A review. Compr. Rev. Food Sci. Food Saf. 2020, 19, 2139-2163. [CrossRef]

10. Perry, J.R.; Ying, W. A Review of Physiological Effects of Soluble and Insoluble Dietary Fibers. A Review of Physiological Effects of Soluble and Insoluble Dietary Fibers. J. Nutr. Food Sci. 2016, 6, 476. [CrossRef]

11. Fuller, S.; Beck, E.; Salman, H.; Tapsell, L. New Horizons for the Study of Dietary Fiber and Health: A Review. Plant Foods Hum. Nutr. 2016, 71, 1-12. [CrossRef]

12. Ain, H.B.U.; Saeed, F.; Ahmed, A.; Khan, M.A.; Niaz, B.; Tufail, T. Improving the physicochemical properties of partially enhanced soluble dietary fiber through innovative techniques: A coherent review. J. Food Process. Preserv. 2019, 43, e13917. [CrossRef]

13. Ozyurt, V.H.; Ötles, S. Effect of food processing on the physicochemical properties of dietary fibre. Acta Sci. Pol. Technol. Aliment. 2016, 15, 233-245. [CrossRef] [PubMed]

14. Gan, J.; Xie, L.; Peng, G.; Xie, J.; Chen, Y.; Yu, Q. Systematic review on modification methods of dietary fiber. Food Hydrocoll. 2021, 119, 106872. [CrossRef]

15. Wu, W.; Hu, J.; Gao, H.; Chen, H.; Fang, X.; Mu, H.; Han, Y.; Liu, R. The potential cholesterol-lowering and prebiotic effects of bamboo shoot dietary fibers and their structural characteristics. Food Chem. 2020, 332, 127372. [CrossRef] [PubMed]

16. Liu, J.; Wang, Z.; Wang, Z.; Hao, Y.; Wang, Y.; Yang, Z.; Li, W.; Wang, J. Physicochemical and functional properties of soluble dietary fiber from different colored quinoa varieties (Chenopodium quinoa Willd). J. Cereal Sci. 2020, 95, 103045. [CrossRef]

17. Ma, R.; Chen, J.-N.; Zhou, X.-J.; Lin, H.; Gao, Q.; Peng, X.; Tanokura, M.; Xue, Y.-L. Effect of chemical and enzymatic modifications on the structural and physicochemical properties of dietary fiber from purple turnip (Brassica rapa L.). LWT 2021, 145, 111313. [CrossRef]

18. Shen, M.; Weihao, W.; Cao, L. Soluble dietary fibers from black soybean hulls: Physical and enzymatic modification, structure, physical properties, and cholesterol binding capacity. J. Food Sci. 2020, 85, 1668-1674. [CrossRef]

19. Chandrasekara, A.; Shahidi, F. Content of Insoluble Bound Phenolics in Millets and Their Contribution to Antioxidant Capacity. J. Agric. Food Chem. 2010, 58, 6706-6714. [CrossRef]

20. Ruiz-Torralba, A.; Guerra-Hernández, E.J.; García-Villanova, B. Antioxidant capacity, polyphenol content and contribution to dietary intake of 52 fruits sold in Spain. CyTA -J. Food 2018, 16, 1131-1138. [CrossRef]

21. Okolie, C.L.; Mason, B.; Mohan, A.; Pitts, N.; Udenigwe, C.C. The comparative influence of novel extraction technologies on in vitro prebiotic-inducing chemical properties of fucoidan extracts from Ascophyllum nodosum. Food Hydrocoll. 2018, 90, 462-471. [CrossRef]

22. Akbari-Alavijeh, S.; Soleimanian-Zad, S.; Sheikh-Zeinoddin, M.; Hashmi, S. Pistachio hull water-soluble polysaccharides as a novel prebiotic agent. Int. J. Biol. Macromol. 2018, 107, 808-816. [CrossRef] [PubMed]

23. Du, X.; Wang, L.; Huang, X.; Jing, H.; Ye, X.; Gao, W.; Bai, X.; Wang, H. Effects of different extraction methods on structure and properties of soluble dietary fiber from defatted coconut flour. LWT 2021, 143, 111031. [CrossRef]

24. Yan, L.; Li, T.; Liu, C.; Zheng, L. Effects of high hydrostatic pressure and superfine grinding treatment on physicochemical/ functional properties of pear pomace and chemical composition of its soluble dietary fibre. LWT 2019, 107, 171-177. [CrossRef]

25. Wang, L.; Xu, H.; Yuan, F.; Pan, Q.; Fan, R.; Gao, Y. Physicochemical characterization of five types of citrus dietary fibers. Biocatal. Agric. Biotechnol. 2015, 4, 250-258. [CrossRef]

26. Hao, L.; Lu, X.; Sun, M.; Li, K.; Shen, L.; Wu, T. Protective effects of L-arabinose in high-carbohydrate, high-fat diet-induced metabolic syndrome in rats. Food Nutr. Res. 2015, 59, 28886. [CrossRef]

27. Tamura, M.; Kurusu, Y.; Hori, S. Effect of Dietary L-arabinose on the Intestinal Microbiota and Metabolism of Dietary Daidzein in Adult Mice. Biosci. Microbiota Food Heal. 2012, 31, 59-65. [CrossRef] [PubMed]

28. Wandee, Y.; Uttapap, D.; Mischnick, P. Yield and structural composition of pomelo peel pectins extracted under acidic and alkaline conditions. Food Hydrocoll. 2019, 87, 237-244. [CrossRef]

29. Qi, J.; Yokoyama, W.; Masamba, K.G.; Majeed, H.; Zhong, F.; Li, Y. Structural and physico-chemical properties of insoluble rice bran fiber: Effect of acid-base induced modifications. RSC Adv. 2015, 5, 79915-79923. [CrossRef]

30. Wang, K.; Li, M.; Wang, Y.; Liu, Z.; Ni, Y. Effects of extraction methods on the structural characteristics and functional properties of dietary fiber extracted from kiwifruit (Actinidia deliciosa). Food Hydrocoll. 2020, 110, 106162. [CrossRef]

31. Lyu, B.; Wang, H.; Swallah, M.S.; Fu, H.; Shen, Y.; Guo, Z.; Tong, X.; Li, Y.; Yu, H.; Jiang, L. Structure, Properties and Potential Bioactivities of High-purity Insoluble Fibre from Soybean Dregs (Okara). Food Chem. 2021, 364, 130402. [CrossRef] [PubMed]

32. Chen, H.; Xiong, M.; Bai, T.; Chen, D.; Zhang, Q.; Lin, D.; Liu, Y.; Liu, A.; Huang, Z.; Qin, W. Comparative study on the structure, physicochemical, and functional properties of dietary fiber extracts from quinoa and wheat. LWT 2021, 149, 111816. [CrossRef]

33. Wen, Y.; Niu, M.; Zhang, B.; Zhao, S.; Xiong, S. Structural characteristics and functional properties of rice bran dietary fiber modified by enzymatic and enzyme-micronization treatments. LWT-Food Sci. Technol. 2017, 75, 344-351. [CrossRef]

34. Chen, Y.; Ye, R.; Yin, L.; Zhang, N. Novel blasting extrusion processing improved the physicochemical properties of soluble dietary fiber from soybean residue and in vivo evaluation. J. Food Eng. 2014, 120, 1-8. [CrossRef]

35. Lettow, M.; Grabarics, M.; Mucha, E.; Thomas, D.A.; Polewski, L.; Freyse, J.; Rademann, J.; Meijer, G.; Von Helden, G.; Pagel, K. IR action spectroscopy of glycosaminoglycan oligosaccharides. Anal. Bioanal. Chem. 2020, 412, 533-537. [CrossRef] 
36. Zhao, X.; Chen, J.; Chen, F.; Wang, X.; Zhu, Q.; Ao, Q. Surface characterization of corn stalk superfine powder studied by FTIR and XRD. Colloids Surf. B Biointerfaces 2013, 104, 207-211. [CrossRef]

37. Li, N.; Feng, Z.; Niu, Y.; Yu, L. Structural, rheological and functional properties of modified soluble dietary fiber from tomato peels. Food Hydrocoll. 2018, 77, 557-565. [CrossRef]

38. Alfredo, V.-O.; Gabriel, R.-R.; Luis, C.-G.; David, B.-A. Physicochemical properties of a fibrous fraction from chia (Salvia hispanica L.). LWT-Food Sci. Technol. 2008, 42, 168-173. [CrossRef]

39. Zhu, K.; Huang, S.; Peng, W.; Qian, H.; Zhou, H. Effect of ultrafine grinding on hydration and antioxidant properties of wheat bran dietary fiber. Food Res. Int. 2010, 43, 943-948. [CrossRef]

40. Rosell, C.M.; Santos, E.; Collar, C. Physico-chemical properties of commercial fibres from different sources: A comparative approach. Food Res. Int. 2008, 42, 176-184. [CrossRef]

41. Twarogowska, A.; Van Poucke, C.; Van Droogenbroeck, B. Upcycling of Belgian endive (Cichorium intybus var. foliosum) by-products. Chemical composition and functional properties of dietary fibre root powders. Food Chem. 2020, 332, 127444. [CrossRef] [PubMed]

42. Feng, Z.; Dou, W.; Alaxi, S.; Niu, Y.; Yu, L.L. Modified soluble dietary fiber from black bean coats with its rheological and bile acid binding properties. Food Hydrocoll. 2017, 62, 94-101. [CrossRef]

43. Cheng, L.; Zhang, X.; Hong, Y.; Li, Z.; Li, C.; Gu, Z. Characterisation of physicochemical and functional properties of soluble dietary fibre from potato pulp obtained by enzyme-assisted extraction. Int. J. Biol. Macromol. 2017, 101, 1004-1011. [CrossRef] [PubMed]

44. Dhital, S.; Dolan, G.; Stokes, J.R.; Gidley, M.J. Enzymatic hydrolysis of starch in the presence of cereal soluble fibre polysaccharides Food Funct. 2014, 5, 579-586. [CrossRef] [PubMed]

45. Chen, H.; Pu, J.; Liu, D.; Yu, W.; Shao, Y.; Yang, G.; Xiang, Z.; He, N. Anti-Inflammatory and Antinociceptive Properties of Flavonoids from the Fruits of Black Mulberry (Morus nigra L.). PLoS ONE 2016, 11, e0153080. [CrossRef]

46. Deng, J.-S.; Chi, C.-S.; Huang, S.-S.; Shie, P.-H.; Lin, T.-H.; Huang, G.-J. Antioxidant, analgesic, and anti-inflammatory activities of the ethanolic extracts of Taxillus liquidambaricola. J. Ethnopharmacol. 2011, 137, 1161-1171. [CrossRef] [PubMed]

47. Zhang, R.; Zeng, Q.; Deng, Y.; Zhang, M.; Wei, Z.; Zhang, Y.; Tang, X. Phenolic profiles and antioxidant activity of litchi pulp of different cultivars cultivated in Southern China. Food Chem. 2013, 136, 1169-1176. [CrossRef]

48. Guo, W.; Beta, T. Phenolic acid composition and antioxidant potential of insoluble and soluble dietary fibre extracts derived from select whole-grain cereals. Food Res. Int. 2013, 51, 518-525. [CrossRef]

49. Hu, S.; Yin, J.; Nie, S.; Wang, J.; Phillips, G.O.; Xie, M.; Cui, S.W. In vitro evaluation of the antioxidant activities of carbohydrates. Bioact. Carbohydr. Diet. Fibre 2016, 7, 19-27. [CrossRef]

50. Chen, G.; Chen, X.; Yang, B.; Yu, Q.; Wei, X.; Ding, Y.; Kan, J. New insight into bamboo shoot (Chimonobambusa quadrangularis) polysaccharides: Impact of extraction processes on its prebiotic activity. Food Hydrocoll. 2019, 95, 367-377. [CrossRef]

51. Tadayoni, M.; Sheikh-Zeinoddin, M.; Soleimanian-Zad, S. Isolation of bioactive polysaccharide from acorn and evaluation of its functional properties. Int. J. Biol. Macromol. 2015, 72, 179-184. [CrossRef]

52. Bai, Y.; Zhao, J.; Tao, S.; Zhou, X.; Pi, Y.; Gerrits, W.J.; Johnston, L.J.; Zhang, S.; Yang, H.; Liu, L.; et al. Effect of dietary fiber fermentation on short-chain fatty acid production and microbial composition in vitro. J. Sci. Food Agric. 2020, 100, $4282-4291$. [CrossRef] [PubMed]

53. Linares, D.M.; Ross, P.; Stanton, C. Beneficial Microbes: The pharmacy in the gut. Bioengineered 2016, 7, 11-20. [CrossRef] [PubMed] 